\title{
HDL subfraction distribution and HDL function in untreated dyslipidemic patients
}

\author{
Mariann Harangi, Anita Szentpéteri, Bíborka Nádró, Hajnalka Lőrincz, Ildikó Seres, Dénes Páll, György Paragh \\ Department of Internal Medicine, University of Debrecen Faculty of Medicine, H-4032 Debrecen, Hungary.
}

Correspondence to: Dr. Mariann Harangi, Department of Internal Medicine, University of Debrecen Faculty of Medicine, Nagyerdei krt. 98, H-4032 Debrecen, Hungary. E-mail: mharangi@hotmail.com

How to cite this article: Harangi M, Szentpéteri A, Nádró B, Lőrincz H, Seres I, Páll D, Paragh G. HDL subfraction distribution and HDL function in untreated dyslipidemic patients. Vessel Plus 2017;1:166-73.

\section{Article history: \\ Received: 31 Jul 2017 \\ Accepted: 18 Sep 2017 \\ Published: 28 Dec 2017}

\section{Key words:}

High-density lipoprotein,

subfraction,

paraoxonase,

myeloperoxidase,

dyslipidemia

\section{INTRODUCTION}

High-density lipoprotein (HDL) is a fraction of small, dense, protein-rich lipoprotein that is highly

\begin{abstract}
Aim: The protective role of high-density lipoprotein (HDL) against atherosclerosis is well known. However, both structural and functional changes of the HDL particles may affect its protective efficacy. Increased levels of HDL-associated myeloperoxidase (MPO) and decreased HDL-linked paraoxonase-1 (PON1) activity have been reported in dyslipidemic patients. Some changes in HDL subfraction distributions were also studied previously, but data on structural and functional changes in dyslipidemia are not complete. Therefore, the authors aimed to evaluate these qualitative and quantitative markers of HDL in dyslipidemic patients and healthy control subjects. Methods: Anthropometric parameters, serum levels of lipoproteins and MPO, as well as PON1 activities were investigated in 81 untreated dyslipidemic patients and in 32 healthy gender-matched controls. Additionally, HDL subfractions were detected by an electrophoretic method on polyacrylamide gel (Lipoprint). Results: Significantly higher glucose, hemoglobin A1c, total cholesterol, low-density lipoprotein-cholesterol, triglyceride, lipoprotein(a), apolipoprotein B, C-reactive protein, and MPO levels were found in patients compared to the healthy subjects. There were no significant differences in PON1 paraoxonase and arylesterase activities between the two study groups, but MPO/PON1 ratio was significantly higher in patients. There was a shift towards the smaller HDL subfractions, but only the intermediate HDL ratio was significantly lower in patients compared to controls. Conclusion: The results highlight the importance of HDL-associated pro- and antioxidant enzymes suggesting the possible clinical benefit of MPO/PON1 calculation and confirm that quantification of HDL-C level alone provides limited data regarding HDL's cardioprotective effect. Calculation of MPO/PON1 ratio may be a useful cardiovascular marker in dyslipidemia.
\end{abstract}

heterogeneous in their structural, chemical and biological properties. Using different analytical methods HDL can be separated to subclasses differing in size, density, shape and lipid and protein

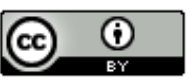

This is an open access article licensed under the terms of Creative Commons Attribution 4.0 International License (https://creativecommons.org/licenses/by/4.0/), which permits unrestricted use, distribution, and reproduction in any medium, as long as the original author is credited and the new creations are licensed under the identical terms.

For reprints contact: service@oaepublish.com

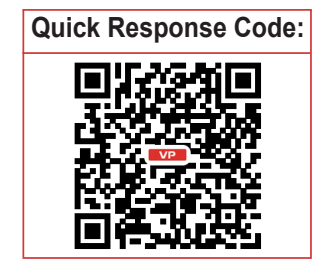


composition ${ }^{[1]}$. Therefore, the subfraction distribution of HDL has implications for their functions. Although the compositional and functional heterogeneity of HDL particles is well known, HDL is often regarded as a single entity characterized by measurement of HDLcholesterol (HDL-C) levels. Previous epidemiological studies have clearly shown that levels of HDL-C are inversely associated with the risk of coronary artery disease and its thrombotic complications ${ }^{[2,3]}$. Over the last few decades, substantial progress has been made in understanding how the HDL particle exerts protective effects on the vessel wall. HDL and its main protein constituent, apolipoprotein A1 (ApoA1) is protective in processes involved in atherogenesis, including mediation of reverse cholesterol transport, protection against oxidative stress, and inhibition of cytokine-induced expression of cellular adhesion molecules on endothelial cells. However, under particular circumstances, HDL particles may become dysfunctional caused by the loss of antioxidant and anti-inflammatory proteins in combination with a gain of acute phase proteins and some further proinflammatory components. This pro-inflammatory, dysfunctional HDL is unable to protect low-density lipoprotein (LDL) from oxidation and to prevent monocyte migration into the vessel wall induced by oxidized LDL particles ${ }^{[4]}$. Myeloperoxidase (MPO) mediates the oxidation of ApoA1 that creates a dysfunctional HDL particle, which activates nuclear factor kappa-B and promotes inflammation in the vessel wall ${ }^{[5]}$. MPO level and its role in oxidative stress and inflammation has been implicated in the pathophysiology of cardiovascular diseases such as coronary artery disease ${ }^{[6]}$. Human paraoxonase-1 (PON1) is a calcium-dependent lactonase that is produced by the liver and almost exclusively associated with $\mathrm{HDL}^{[7]}$. Although hydrolysis of homocysteine thiolactone might represent a major physiologic function of $\mathrm{PON} 1^{[8]}$, several further substrates have been described including other lactones ${ }^{[9]}$, organophosphates and lipid peroxides ${ }^{[7]}$. Interestingly, some previous studies proved that PON1 is predominantly associated to the smaller and denser HDL3 subfractions, and PON1 activity of HDL2 was only $4 \%$ of that in $\mathrm{HDL}^{[10]}$. Furthermore, previous data indicate that MPO, PON1 and HDL from a functional ternary complex in which MPO and PON1 inhibit each other's activity demonstrating the dysfunction of the HDL particle ${ }^{[11]}$.

Dyslipidemia characterized by high levels of triglyceride, total and LDL cholesterol is an established risk factor for coronary heart disease. Therefore, to reduce the risk of cardiovascular complications lipid lowering treatment is widely used in this patient population. Additionally, combined forms of hyperlipidemia often require combined drug therapy. At the same time, it must be noted that lipid lowering agents, such as statins ${ }^{[12,13]}$, fibrates ${ }^{[14]}$ and ezetimibe ${ }^{[15]}$ have a significant effect on HDL composition and function. Consequently, evaluating the effect of various lipid abnormalities on HDL properties in patients on lipid lowering therapy can be misleading ${ }^{[16]}$.

Therefore, we investigated the structural and some functional HDL properties in newly diagnosed, untreated dyslipidemic patients and in healthy controls to evaluate the effect of dyslipidemia on the structural and functional properties of HDL characterized by the serum levels of HDL subfractions and MPO, PON1 paraoxonase and arylesterase activities and PON1 phenotyping. We hypothesized that the level and ratio of large HDL subfractions are higher, and the level and ratio smaller HDL subfractions are lower in dyslipidemic subjects compared to healthy controls. A lower number of smaller HDL subfractions may result in lower PON activities and higher MPO levels.

\section{METHODS}

\section{Study population}

The study protocol was approved by local and regional ethics committees and carried out in accordance with the Declaration of Helsinki of World Medical Association. All investigated subjects gave their written informed consent to participate in the study. We enrolled eighty-one newly diagnosed, untreated patient with Fredrickson type Ila and IIb hyperlipidemia that were referred to our lipid outpatient clinic at Department of Internal Medicine, University of Debrecen. Physical examination and carotid ultrasound were performed regularly. Further vascular imaging techniques (Doppler ultrasound and computer tomography) were performed in case of complaints or abnormal physical and electrocardiography examinations.

We excluded patients with pre-existing vascular complications from the study. Vascular complications were defined as ischemic heart disease (myocardial infarction or coronary sclerosis), ischemic cerebrovascular disease (ischemic stroke, transient ischemic attack, carotid artery stenosis/occlusion) and peripheral arterial disease. Vascular complications were established by patient history or upon the results of imaging techniques. Any lesions with measurable intravascular stenosis were defined as clinically significant. Further exclusion criteria included previous and ongoing lipid lowering therapy, chronic inflammatory conditions, autoimmune disease, and 
endocrine or active liver disease including type 1 and 2 diabetes mellitus, chronic renal disease and malignancy.

Furthermore, thirty-two individuals were enrolled as a control population confirmed to be healthy by clinical and laboratory examinations.

\section{Biochemical assays}

After an overnight fasting period venous blood samples were taken into evacuated tubes and sera were prepared immediately by centrifugation at $1,500 \times g$ for $10 \mathrm{~min}$ at $4{ }^{\circ} \mathrm{C}$. Multiple aliquots of each samples were separated and stored at $-70{ }^{\circ} \mathrm{C}$. Routine laboratory analyses: total cholesterol, HDL-C, LDL-cholesterol (LDL-C), C-reactive protein (CRP), triglyceride, ApoA1, apolipoprotein B (ApoB), lipoprotein(a), hemoglobin A1c (HbA1c), and supersensitive thyroid stimulating hormone were performed from fresh sera with Cobas c501 autoanalyzer (Roche Ltd., Mannheim, Germany) in the Department of Laboratory Medicine of University of Debrecen. Tests were performed according to the recommendation of the manufacturer. All the reagents were purchased from the same vendor.

\section{Paraoxonase- 1 activities and phenotype}

PON1 paraoxonase activity was measured by a kinetic, semi-automated method. Briefly, paraoxon (O,O-diethyl-O-p-nitrophenyl-phosphate, Sigma, Hungary) was used as a substrate, and the generation of 4-nitrophenol was measured on a microtiter plate (Greiner Bio-One $\mathrm{GmbH}$, Germany). The total of $15 \mu \mathrm{L}$ serum was mixed with $285 \mu \mathrm{L}$ Tris- $\mathrm{HCl}$ buffer (100 mmol/L, $\mathrm{pH}=8.0$ ) containing $2 \mathrm{mmol} / \mathrm{L} \mathrm{CaCl}{ }_{2}$ and $5.5 \mathrm{mmol} / \mathrm{L}$ paraoxon. The absorbance was monitored at $405 \mathrm{~nm}\left(25^{\circ} \mathrm{C}\right)$, in every minute for 6 min by a Beckman Coulter DTX880 Plate Reader (Beckman Coulter, California, USA) equipped with multimode detector. Enzyme activity was calculated using the molar extinction coefficient $17,600 \mathrm{M}^{-1} \mathrm{~cm}^{-1}$. PON1 paraoxonase activity is expressed as units per liter of serum, where 1 unit equals $1 \mu \mathrm{mol}$ of substrate hydrolyzed per minute.

PON1 arylesterase activity was assayed by a standard containing $1 \mathrm{mmol} / \mathrm{L}$ phenylacetate substrate (Sigma, Hungary) in $20 \mathrm{mmol} / \mathrm{L}$ Tris $-\mathrm{HCl}, \mathrm{pH}=8.0$. The reaction was started by adding the serum and the absorbance was monitored at $270 \mathrm{~nm}$. Blanks were included to correct for the spontaneous hydrolysis of phenylacetate. We calculated the enzyme activity using the molar extinction coefficient $1,310 \mathrm{M}^{-1} \mathrm{~cm}^{-1}$. PON1 arylesterase activity is expressed in $\mathrm{U} / \mathrm{mL}$; $1 \mathrm{U}$ is defined as $1 \mu \mathrm{mol}$ phenylacetate hydrolyzed per minute.

To calculate PON1 phenotype the dual substrate method was used ${ }^{[17]}$. The genetic polymorphism at codon $192 \mathrm{Q} \rightarrow \mathrm{R}(\mathrm{Arg} / \mathrm{Gln}$ at position 192) has the most significant impact on the enzyme activity as hydrolysis of paraoxon is faster by the $R$ allele than by the $Q$ allele. The allozyme determined by the $R$ allele was designated type $B$, while the allozyme identified by the $Q$ allele was nominated type $A$. In contrast, both $R$ and $Q$ alleles had similar arylesterase activity. The ratio of the hydrolysis of paraoxon in the presence of $1 \mathrm{~mol} / \mathrm{L} \mathrm{NaCl}$ (salt-stimulated paraoxonase) to the hydrolysis of phenylacetate was used to assign individuals to one of the three possible PON1 phenotypes: AA (low activity), AB (intermediate activity) and $B B$ (high activity). Cut-off values between phenotypes were as follows: ratio below 3.0 for $A A$, ratio between 3.0 and 7.0 for $A B$ and ratio over 7.0 for BB phenotype.

\section{Serum myeloperoxidase concentration measurement}

Myeloperoxidase serum concentrations were measured by commercially available sandwich enzyme-linked immunosorbent assay (ELISA) kits (R\&D Systems Europe Ltd., Abington, England). The ELISA assay was performed according to the manufacturer's instructions. The intra- and inter-assay coefficient of variations was $6.5-9.4 \%$.

\section{HDL subfraction analysis}

HDL subfractions were determined using an electrophoretic method on polyacrylamide gel with the Lipoprint System (Quantimetrix Corp., CA, USA) according to manufacturer's instructions. This commercially available system separates HDL subfractions from human serum on the basis of their size applying preloaded gel tubes for HDL determinations.

Concisely, $25 \mu \mathrm{L}$ serum was added to the polyacrylamide gel tubes along with $300 \mu \mathrm{L}$ loading gel solution. The tubes contained Sudan Black as a lipophilic dye and were photopolimerized at room temperature for $30 \mathrm{~min}$. Electrophoresis with tubes containing sera samples and the manufacturer's quality controls were performed at a constant of $3 \mathrm{~mA} /$ tube for $50 \mathrm{~min}$. Subfraction bands were scanned with an ArtixScan M1 digital scanner (Microtek International Inc., CA, USA) and were identified by their mobility (Rf) using very-LDL (VLDL) + LDL as the starting (Rf 0.0) and albumin as the ending ( $\operatorname{Rf} 1.0$ ) reference point.

Ten HDL subfractions were differentiated between 

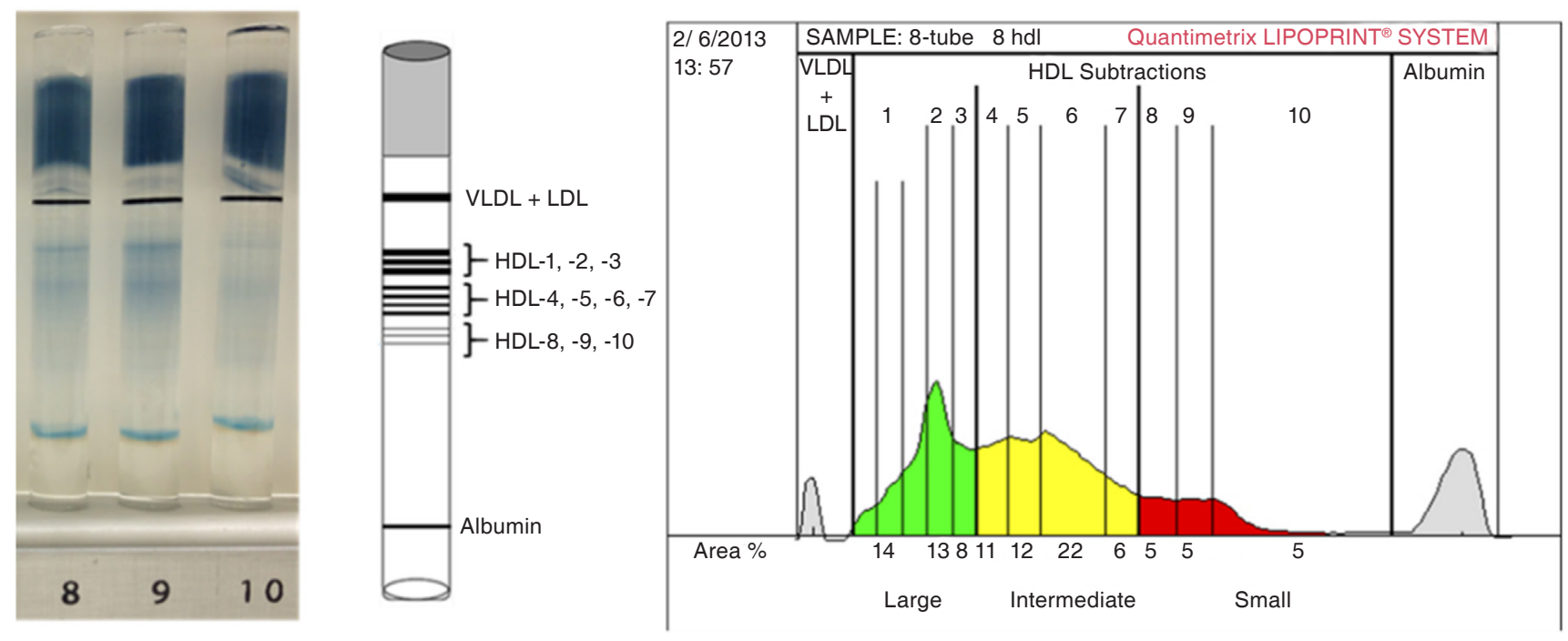

Figure 1: HDL subfraction profile in a healthy subject determined using an electrophoretic method on polyacrylamide gel with the Lipoprint System. Ten HDL subfractions were differentiated between VLDL + LDL and albumin peaks, and were grouped into three major classes: large (from HDL1 to HDL3), intermediate (from HDL4 to HDL7) and small (HDL8 to HDL10) HDL subfractions. HDL: high-density lipoprotein; VLDL: very-low-density lipoprotein

VLDL + LDL and albumin peaks, and were grouped into three major classes: large (from HDL1 to HDL3), intermediate (from HDL4 to HDL7) and small (HDL8 to HDL10) HDL subfractions. Cholesterol concentrations of the HDL particle subsets were calculated by multiplying the total cholesterol concentration of the samples by the relative area under the curve of the subfraction bands [Figure 1].

\section{Statistical methods}

Statistical analysis was performed by STATISTICA (ver 8.0; StatSoft Inc., Tulsa, OK, USA). We tested the normality of data distribution by KolmogorovSmirnov test. Data are presented by descriptive analysis [mean $\pm S D$ in case of normal distribution, or median (lower quartile - upper quartile) in the case of non-normal distribution]. Comparisons between groups were performed by Student's unpaired $t$ test in case of normally distributed variables and by Mann-Whitney $U$-test in case of variables with nonnormal distribution. Correlations between continuous variables were assessed by linear regression analysis using Pearson's test. Differences with $P<0.05$ were considered to be statistically significant.

\section{RESULTS}

Significantly higher total cholesterol, LDL-C, triglyceride, lipoprotein(a), apo B and CRP levels were found in the untreated dyslipidemic patients compared to healthy controls. A few patients had higher CRP levels, however, we could not find significant correlations between the studied parameters and the serum level of CRP. Serum glucose and HbA1c levels were also significantly higher in patients, although they remained in the normal range. Mean age and body mass index of patients were also significantly higher compared to controls. Concentration of serum MPO was significantly higher in patients [Figure 2A] . We could not find significant differences in PON1 paraoxonase and arylesterase activities between the two study groups. Large inter-individual variations in PON1 paraoxonase and arylesterase enzyme activities were found both in dyslipidemic patients and controls [Figure $2 \mathrm{C}$ and $\mathrm{D}$ ]. The MPO/PON1 ratio was significantly higher in dyslipidemic patients compared to controls [Table 1 and Figure 2B].

Significant negative correlation was detected between PON1 arylesterase activity and the concentration of MPO ( $r=-0.38 ; P<0.001)$ in the whole study group (data not shown). Analyzing these associations in the two groups separately, correlation remained significant only in patients $(r=-0.38 ; P<0.001)$. The PON1 phenotype distribution was as follows: in the patient group $80.2 \%(n=65)$ were AA, $19.8 \%(n=16)$ were $A B$ phenotype, and there were no patients with $B B$ phenotype. The phenotype distribution (AA-AB) was $87.5 \%(n=28), 12.5 \%(n=4)$ in controls, respectively. The allelic frequencies followed the Hardy-Weinberg equilibrium and no significant differences were found between the subgroups.

The absolute amounts and ratios of lipoprotein subfractions are shown on Table 2. Although HDL-C levels fell into the normal range in both studied groups, 
A

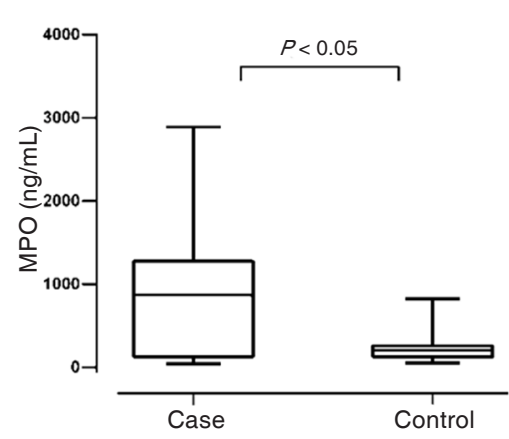

B

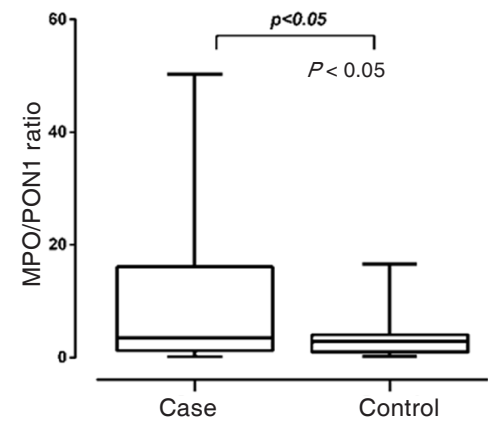

C

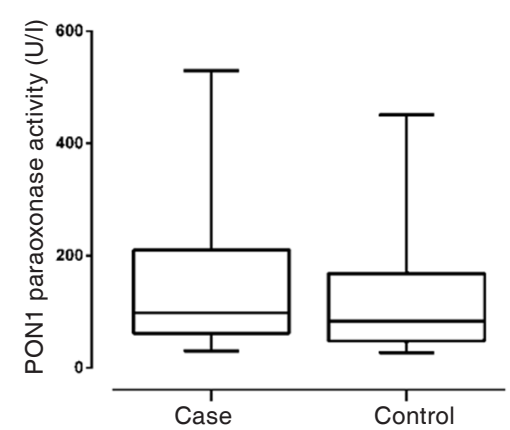

D

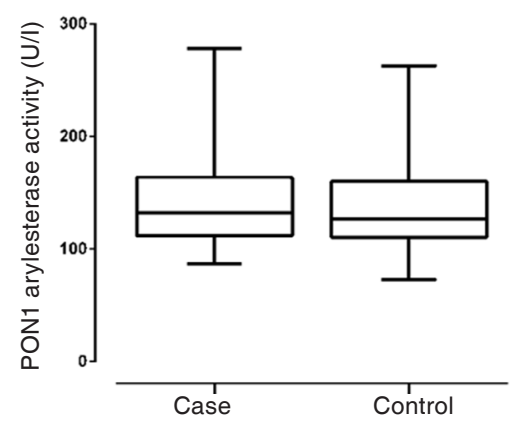

Figure 2: Levels of serum MPO (A), MPO/PON1 ratio (B), activities of serum paraoxonase (C), and arylesterase (D) in dyslipidemic patients and controls. MPO: myeloperoxidase; PON1: paraoxonase-1

Table 1: Laboratory parameters and anthropometric data of the patients and healthy controls

\begin{tabular}{|c|c|c|c|}
\hline & Dyslipidemic patients & Healthy controls & $P$ \\
\hline Number of patients & 81 & 32 & \\
\hline Age (years) & $48.9 \pm 14.3$ & $41.8 \pm 5.9$ & $<0.01$ \\
\hline Female/male & $49 / 32$ & $19 / 13$ & NS \\
\hline $\mathrm{BMI}\left(\mathrm{kg} / \mathrm{m}^{2}\right)$ & $28.1 \pm 5.0$ & $24.5 \pm 2.5$ & $<0.01$ \\
\hline \multicolumn{4}{|l|}{ Waist circumference $(\mathrm{cm})$} \\
\hline Females & $89.4 \pm 13.2$ & $85.7 \pm 6.6$ & $<0.05$ \\
\hline Males & $101.7 \pm 11.2$ & $92.75 \pm 7.6$ & $<0.05$ \\
\hline Glucose (mmol/L) & $5.1(4.8-5.5)$ & $4.8(4.6-5.1)$ & $<0.01$ \\
\hline $\mathrm{HbA1C}(\%)$ & $5.4(5.2-5.9)$ & $5.1(4.8-5.3)$ & $<0.01$ \\
\hline Total cholesterol (mmol/L) & $7.07 \pm 1.69$ & $5.07 \pm 0.78$ & $<0.01$ \\
\hline LDL-C (mmol/L) & $4.52 \pm 1.43$ & $2.92 \pm 0.51$ & $<0.01$ \\
\hline $\mathrm{HDL}-\mathrm{C}(\mathrm{mmol} / \mathrm{L})$ & $1.56 \pm 0.54$ & $1.55 \pm 0.46$ & NS \\
\hline Triglyceride (mmol/L) & $1.6(1.1-3.0)$ & $1.2(0.8-1.4)$ & $<0.01$ \\
\hline Lipoprotein(a) (mg/L) & $191(77-587)$ & $70(30-214)$ & $<0.01$ \\
\hline Apolipoprotein A1 (g/L) & $1.71 \pm 0.59$ & $1.68 \pm 0.31$ & NS \\
\hline Apolipoprotein B (g/L) & $1.33 \pm 0.37$ & $0.94 \pm 0.18$ & $<0.01$ \\
\hline $\mathrm{hsCRP}(\mathrm{mg} / \mathrm{L})$ & $2.4(1.0-45.3)$ & $2.0(0.6-2.9)$ & $<0.05$ \\
\hline Thyroid stimulating hormone (mU/L) & $2.1 \pm 1.29$ & $1.94 \pm 1.1$ & NS \\
\hline Myeloperoxidase $(\mathrm{ng} / \mathrm{mL})$ & $869(131-1,272)$ & $205(125-257)$ & $<0.05$ \\
\hline Paraoxonase activity (U/L) & $98(62-210)$ & $83(48-167)$ & NS \\
\hline Arylesterase activity (U/L) & $132(112-162)$ & $127(110-160)$ & NS \\
\hline Myeloperoxidase/paraoxonase (ug/U) & $3.56(1.28-16.03)$ & $2.81(0.89-4.03)$ & $<0.05$ \\
\hline
\end{tabular}

Data are presented as mean \pm standard deviation or median (lower-upper quartiles). NS: non-significant; BMI: body mass index; HbA1c: hemoglobin A1c; LDL-C: low-density lipoprotein cholesterol; HDL-C: high-density lipoprotein cholesterol; hsCRP: high sensitivity C-reactive protein

there was a shift toward the small-sized HDL particles in dyslipidemic patients compared to controls. The ratio of intermediate HDL subfraction was found to be significantly lower in dyslipidemic patients compared to controls, but there were no further significant differences between patients and controls [Table 2].

\section{DISCUSSION}

The measurement of serum levels of HDL-C has 
Table 2: Concentration and ratio of high-density lipoprotein subfractions in dyslipidemic patients and healthy controls

\begin{tabular}{lccc}
\hline & Dyslipidemic patients & Healthy controls & $\boldsymbol{P}$ \\
\hline HDL subfraction concentrations $(\mathrm{mmol} / \mathrm{L})$ & & & \\
Large HDL & $0.42(0.27-0.67)$ & $0.45(0.31-0.61)$ & $\mathrm{NS}$ \\
Intermediate HDL & $0.73(0.59-0.87)$ & $0.75(0.66-0.85)$ & $\mathrm{NS}$ \\
Small HDL & $0.34(0.23-0.43)$ & $0.28(0.25-0.34)$ & $\mathrm{NS}$ \\
HDL subfraction ratios (\%) & & & $\mathrm{NS}$ \\
Large HDL & $29.7(21.5-35.4)$ & $31.6(24.4-34.6)$ & $<0.05$ \\
Intermediate HDL & $48.3(45-51.4)$ & $51.5(48.3-54.3)$ & $\mathrm{NS}$ \\
Small HDL & $21.6(16.4-26.6)$ & $18.4(15.5-22.5)$ & \\
\hline
\end{tabular}

Values are presented as mean \pm standard deviation or median (lower-upper quartiles). NS: non-significant; HDL: high-density lipoprotein

been standardized and accepted in everyday clinical practice, but it fails to capture the complexity of HDL structure and function. Previous proteomic studies have revealed more than 100 proteins on HDL particles including structure proteins, enzymes, complement components and proteinase inhibitors. It became clear that the protective role of HDL against atherogenesis may relate to its composition as much as to its concentration in the plasma ${ }^{[18]}$. By contrast, there is no accepted gold standard to measure the physical and functional properties of HDL particles, although several tests and assays have been reported in the last few decades ${ }^{[1]}$. Consequently, results of the various studies are often not comparable, confusing and not applicable in clinical practice. Indeed, the assessment of HDL structure and functions has become a high priority novel target to investigate the association between HDL and cardiovascular risk. Therefore, any further data on parallel investigation of HDL subfractions and functional markers may improve our knowledge on this field.

Because of the various techniques used for HDL subfraction detection, it is not surprising that considerable controversy exists as to the clinical usefulness of HDL subfractions for the prediction of cardiovascular risk. Basically, HDL-C includes two major subfractions: lipid-enriched, larger HDL2, which has a major role in reverse cholesterol transport, and protein-enriched, smaller HDL3, whose antiatherogenic role is less clear, but is able to bind several antioxidant enzymes including PON1. Although the results of previous studies are not concordant, a higher ratio of the larger HDL2 particles may protective against atherogenesis, while the smaller subclasses are positively correlated with the risk of cardiovascular disease ${ }^{[19]}$. We found a shift towards the smaller HDL subfractions, which may be unfavorable for our dyslipidemic patients. On the other hand, most of these changes were not significant, therefore the importance of alterations in HDL subfractions might not be crucial, at least in dyslipidemic patients without manifest vascular complications. It must be noted that there can be notable differences in data produced by different analytical techniques applied for HDL subclass analysis. Still, these data may shift the focus from HDL subfractions to HDL function.

Measurement of PON1 activity is an accepted indicator of the HDL antioxidant property and a promising biomarker of HDL function independently of HDL-C levels ${ }^{[20]}$. PON1 inhibits lipoprotein oxidation and macrophage foam cell formation. Moreover, it possesses homocysteine-thiolactonase activity and stimulates macrophage cholesterol efflux that may also be responsible for its anti-atherogenic properties ${ }^{[7]}$. A previous meta-analysis comprising 47 studies reported markedly lower PON1 activities in patients with coronary heart disease than in unaffected controls ${ }^{[21]}$. Decreased paraoxonase activities were found in a number of medical conditions including familial hypercholesterolemia and diabetes mellitus ${ }^{[7]}$. However, it is also well known that paraoxonase activities can vary by over 40 -fold between individuals, in part because of its genetic polymorphisms ${ }^{[22,23]}$. Although many environmental and pharmaceutical modulators of PON1 are known, by far the biggest effect on PON1 activity levels is through these polymorphisms. The coding region PON1-Q192R polymorphism determines a substrate dependent effect on activity. Some substrates e.g. paraoxon are hydrolyzed faster by the R- isoform while others such as phenylacetate and diazoxon are hydrolyzed more rapidly by the Qisoform $^{[22]}$. Therefore using the dual substrate method the PON1-Q192R polymorphism can be evaluated. In the present study we could not find significant differences in PON1 paraoxonase and arylesterase activities between patients and controls, but we also observed the large inter-individual variations in enzyme activities. Therefore, we evaluated the PON1 Q192R phenotype distribution and allelic frequencies. The allelic frequencies followed the Hardy-Weinberg 
equilibrium and no significant differences were found between the subgroups. According to the results, because of the large inter-individual variability, PON1 activity measurement alone might not became a useful biomarker for cardiovascular risk prediction in dyslipidemic patients without vascular complications.

MPO is a leukocyte-derived heme protein that binds to HDL. As a part of the innate immune host defense system, MPO uses hydrogen peroxide to generate an array of reactive oxidant and free radical species such as hypochlorous acid possessing antimicrobial effect. However, these reactive species can also foster oxidative injury to host molecules as well. Indeed, MPO catalyzes generation of nitrating oxidants and promotes both protein modifications and initiates lipid peroxidation leading to enhanced atherosclerosis ${ }^{[24]}$. Plasma, serum, and leukocyte MPO levels have been associated with coronary artery disease ${ }^{[25]}$; incident risk of myocardial infarction, death, and need for revascularization ${ }^{[26,27]}$. In a previous study we found significantly elevated MPO levels in overweight hyperlipidemic patients with or without cardiovascular complications ${ }^{[28]}$. In the present study we also found significantly higher MPO levels in dyslipidemic patients without any vascular complications compared to healthy subjects.

Interestingly, both PON1 and MPO interact at the same site on HDL, reciprocally modulate each other's function, influencing the antioxidant and antiinflammatory function of $\mathrm{HDL}^{[11]}$. Our previous study on a similar patient population also highlighted the importance of this reciprocal inhibition ${ }^{[29]}$. Furthermore, a recent study showed that serum MPO/PON1 ratio may be a potential indicator of dysfunctional highdensity lipoprotein and risk stratification in coronary artery disease ${ }^{[30]}$. Therefore, MPO/PON1 ratio was also calculated and we found significantly higher MPO/ PON1 ratio in our dyslipidemic patients compared to controls indicating an increased risk for cardiovascular complications. Moreover, in line with the results of previous studies, significant negative correlation was found between myeloperoxidase levels and PON1 arylesterase activities that demonstrates the reciprocal inhibition between these two HDL-associated enzymes. Hence, calculation of MPO/PON1 ratio may give information about the function of the enzyme complex and characterize HDL function.

Some limitations of the study must be noted. The power of the study may be reduced because of the relatively small size of the study population. Age was significantly different between the patients and controls, however, we could not find significant correlations between the studied parameters and the age. Therefore, we concluded that age may not influence our results in this study. It must be noted that HDL subfraction ratios are derived secondary parameters that may include additional error based on method of calculation. Data on further HDL functional assays such as HDL cholesterol efflux assay, measurement of lecithin: cholesterol acyltransferase or platelet-activating factor-acetylhydrolase activity would add further information on HDL property.

In summary, we found altered HDL function in dyslipidemic patients, characterized by increased level of MPO and MPO/PON1, even in patients without clinically detectable symptoms of vascular complications. However, PON1 paraoxonase and arylesterase activities were unaltered. There was a shift towards the smaller HDL subfractions, but these changes were not significant; indicating that the importance of alterations in HDL subfractions might not be crucial in patients with dyslipidemia. Our results highlights the importance of HDL-associated pro- and antioxidant enzymes suggesting the possible clinical benefit of MPO/PON1 calculation and confirms that quantification of HDL-C level alone provides limited data regarding HDL's cardioprotective effect. Further studies on larger patient populations are needed to identify and characterize the best markers of HDL functions.

Data on HDL structural and functional properties may improve the efficacy of cardiovascular risk prediction and development of novel anti-atherogenic treatment strategies in dyslipidemia.

\section{DECLARATIONS}

\section{Authors' contributions}

Study design: M. Harangi, G Paragh

Development of methodology: I. Seres

Collection of data: B. Nádró, M. Harangi

Analysis and/or interpretation of data: A. Szentpéteri, H. Lőrincz

Writing (not revising) all or sections of the manuscript: M. Harangi

Manuscript review: G. Paragh, D. Páll

Supervision: G. Paragh

\section{Financial support and sponsorship}

This research was supported by a grant from the National Research, Development and Innovation (NFKI) (OTKA 115723) and by the GINOP-2.3.2-15-2016-00062 project. The project is co-financed by the European Union under the European Regional Development Fund. 


\section{Conflicts of interest}

There are no conflicts of interest.

\section{Patient consent \\ Informed consent was obtained from all patients after approval of the local ethics committee.}

\section{Ethics approval}

The study was approved by local and regional ethics committees.

\section{REFERENCES}

1. Hafiane A, Genest J. High density lipoproteins: Measurement techniques and potential biomarkers of cardiovascular risk. BBA Clin 2015;3:175-88.

2. Yusuf S, Hawken S, Ounpuu S, Dans T, Avezum A, Lanas F, McQueen M, Budaj A, Pais P, Varigos J, Lisheng L; INTERHEART Study Investigators. Effect of potentially modifiable risk factors associated with myocardial infarction in 52 countries (the INTERHEART study): case-control study. Lancet 2004;364:937-52.

3. Ramirez A, Hu PP. Low high-density lipoprotein and risk of myocardial infarction. Clin Med Insights Cardiol 2015;9:113-7.

4. Annema W, von Eckardstein A. Dysfunctional high-density lipoproteins in coronary heart disease: implications for diagnostics and therapy. Transl Res 2016;173:30-57.

5. Huang Y, DiDonato JA, Levison BS, Schmitt D, Li L, Wu Y, Buffa J, Kim T, Gerstenecker GS, Gu X, Kadiyala CS, Wang Z, Culley MK, Hazen JE, Didonato AJ, Fu X, Berisha SZ, Peng D, Nguyen TT, Liang S, Chuang CC, Cho L, Plow EF, Fox PL, Gogonea V, Tang WH, Parks JS, Fisher EA, Smith JD, Hazen SL. An abundant dysfunctional apolipoprotein A1 in human atheroma. Nat Med 2014;20:193-203.

6. Khine HW, Teiber JF, Haley RW, Khera A, Ayers CR, Rohatgi A. Association of the serum myeloperoxidase/high-density lipoprotein particle ratio and incident cardiovascular events in a multi-ethnic population: observations from the dallas heart study. Atherosclerosis 2017;263:156-62.

7. Mackness M, Mackness B. Human paraoxonase-1 (PON1): Gene structure and expression, promiscuous activities and multiple physiological roles. Gene 2015;567:12-21

8. Perła-Kaján J, Jakubowski H. Paraoxonase 1 and homocysteine metabolism. Amino Acids 2012;43:1405-17.

9. Ben-David M, Elias M, Filippi JJ, Duñach E, Silman I, Sussman JL, Tawfik DS. Catalytic versatility and backups in enzyme active sites: the case of serum paraoxonase 1. J Mol Biol 2012;418:181-96.

10. Gugliucci A, Menini T. Paraoxonase 1 and HDL maturation. Clin Chim Acta 2015;439:5-13.

11. Huang Y, Wu Z, Riwanto M, Gao S, Levison BS, Gu X, Fu X, Wagner MA, Besler C, Gerstenecker G, Zhang R, Li XM, DiDonato AJ, Gogonea V, Tang WH, Smith JD, Plow EF, Fox PL, Shih DM, Lusis AJ, Fisher EA, DiDonato JA, Landmesser U, Hazen SL. Myeloperoxidase, paraoxonase-1, and HDL form a functional ternary complex. J Clin Invest 2013;123:3815-28.

12. Harangi M, Mirdamadi HZ, Seres I, Sztanek F, Molnár M, Kassai A, Derdák Z, Illyés L, Paragh G. Atorvastatin effect on the distribution of high-density lipoprotein subfractions and human paraoxonase activity. Transl Res 2009;153:190-8.

13. Ferretti G, Bacchetti T, Sahebkar A. Effect of statin therapy on paraoxonase-1 status: A systematic review and meta-analysis of 25 clinical trials. Prog Lipid Res 2015;60:50-73.

14. Balogh Z, Seres I, Harangi M, Kovács P, Kakuk G, Paragh G.
Gemfibrozil increases paraoxonase activity in type 2 diabetic patients. A new hypothesis of the beneficial action of fibrates? Diabetes Metab 2001;27:604-10.

15. Nakou ES, Filippatos TD, Kiortsis DN, Derdemezis CS, Tselepis AD, Mikhailidis DP, Elisaf MS. The effects of ezetimibe and orlistat, alone or in combination, on high-density lipoprotein (HDL) subclasses and HDL-associated enzyme activities in overweight and obese patients with hyperlipidaemia. Expert Opin Pharmacother 2008;9:3151-8.

16. Harangi M, Seres I, Harangi J, Paragh G. Benefits and difficulties in measuring HDL subfractions and human paraoxonase-1 activity during statin treatment. Cardiovasc Drugs Ther 2009;23:501-10.

17. Smolen A, Eckerson HW, Gan KN, Hailat N, La Du BN. Characteristics of the genetically determined allozymic forms of human serum paraoxonase/arylesterase. Drug Metab Dispos 1991;19:107-12.

18. Schaefer EJ, Anthanont P, Asztalos BF. High-density lipoprotein metabolism, composition, function, and deficiency. Curr Opin Lipidol 2014;25:194-9.

19. Li JJ, Zhang Y, Li S, Cui CJ, Zhu CG, Guo YL, Wu NQ, Xu RX, Liu G, Dong Q, Sun J. Large HDL subfraction but not HDL-C is closely linked with risk factors, coronary severity and outcomes in a cohort of nontreated patients with stable coronary artery disease: a prospective observational study. Medicine (Baltimore) 2016;95:e2600.

20. Soran H, Schofield JD, Durrington PN. Antioxidant properties of HDL. Front Pharmacol 2015;6:222.

21. Wang M, Lang X, Cui S, Zou L, Cao J, Wang S, Wu X. Quantitative assessment of the influence of paraoxonase 1 activity and coronary heart disease risk. DNA Cell Biol 2012;31:975-82.

22. Mackness B, Turkie W, Mackness M. Paraoxonase-1 (PON1) promoter region polymorphisms, serum PON1 status and coronary heart disease. Arch Med Sci 2013;9:8-13.

23. Hernández-Díaz Y, Tovilla-Zárate CA, Juárez-Rojop IE, GonzálezCastro TB, Rodríguez-Pérez C, López-Narváez ML, Rodríguez-Pérez JM, Cámara-Álvarez JF. Effects of paraoxonase 1 gene polymorphisms on heart diseases: systematic review and meta-analysis of 64 casecontrol studies. Medicine (Baltimore) 2016;95:e5298.

24. Zhou B, Zu L, Chen Y, Zheng X, Wang Y, Pan B, Dong M, Zhou E, Zhao M, Zhang Y, Zheng L, Gao W. Myeloperoxidase-oxidized high density lipoprotein impairs atherosclerotic plaque stability by inhibiting smooth muscle cell migration. Lipids Health Dis 2017;16:3.

25. Teng N, Maghzal GJ, Talib J, Rashid I, Lau AK, Stocker R. The roles of myeloperoxidase in coronary artery disease and its potential implication in plaque rupture. Redox Rep 2017;22:51-73.

26. Baldus S, Heeschen C, Meinertz T, Zeiher AM, Eiserich JP, Münzel T, Simoons ML, Hamm CW; CAPTURE Investigators. Myeloperoxidase serum levels predict risk in patients with acute coronary syndromes. Circulation 2003;108:1440-5.

27. Brennan ML, Penn MS, Van Lente F, Nambi V, Shishehbor MH, Aviles RJ, Goormastic M, Pepoy ML, McErlean ES, Topol EJ, Nissen SE, Hazen SL. Prognostic value of myeloperoxidase in patients with chest pain. N Engl J Med 2003;349:1595-604.

28. Szentpéteri A, Zsíros N, Varga VE, Lőrincz H, Katkó M, Seres I, Fülöp P, Paragh G, Harangi M. Paraoxonase-1 and myeloperoxidase correlate with vascular biomarkers in overweight patients with newly diagnosed untreated hyperlipidaemia. Vasa 2017;46:370-6.

29. Zsíros N, Koncsos P, Lőrincz H, Seres I, Katkó M, Szentpéteri A, Varga VE, Fülöp P, Paragh G, Harangi M. Paraoxonase-1 arylesterase activity is an independent predictor of myeloperoxidase levels in overweight patients with or without cardiovascular complications. Clin Biochem 2016;49:862-7.

30. Haraguchi $Y$, Toh R, Hasokawa M, Nakajima H, Honjo T, Otsui K, Mori K, Miyamoto-Sasaki M, Shinohara M, Nishimura K, Ishida T, Hirata $\mathrm{K}$. Serum myeloperoxidase/paraoxonase 1 ratio as potential indicator of dysfunctional high-density lipoprotein and risk stratification in coronary artery disease. Atherosclerosis 2014;234:288-94. 